\title{
A moda do sertão: uma construção de identidade nacional a partir da canção "Luar do Sertão"*
}

\author{
Country fashion: a construction of national \\ identity through the song "Luar do Sertão" \\ por Káritha Bernardo de Macedo
}

\begin{abstract}
RESUMO
A canção "Luar do Sertão" (1914), um ícone da música sertaneja, teve papel preponderante na delimitação e disseminação de uma visão da população rural e interiorana brasileira desde seu lançamento, reverberando essas características sobre os designers de nosso tempo, que as reinterpretam conforme as negociações vigentes de identidade sertaneja e urbana. Para tanto, foi analisado o fonograma de "Luar do Sertão", selecionadas algumas características principais e comparadas com a leitura do sistema de moda nacional acerca do tema "sertanejo", fundamentada pela seleção de imagens de coleções de moda brasileira que o abordavam. Deste modo, o que se percebe de forma mais imediata, é que os estilistas brasileiros atuais, de forma estereotipada e distante da realidade, associam a este estilo o padrão da simplicidade, da tranquilidade, do trabalho artesanal, das cores terrosas, e de uma certa inocência quando comparado ao cidadão urbano. Representando ainda, um local de busca pelas raízes nacionais.
\end{abstract}

Palavras-chave Moda; Identidade; Sertanejo; "Luar do Sertão"

\section{ABSTRACT}

The song "Luar do Sertão" (1914), an icon of country music, played an important role in defining and disseminating a vision of Brazil's countrified and provincial population since its release, echoing those features on designers of our time, which reinterpret them according to the current negotiations of urban and country identity.

Therefore we analyzed the phonogram of "Luar do Sertão", selected a number of key features and compared with the interpretation of national fashion system on the theme of "hillbilly", founded by the selection of images from Brazilian fashion collections that addresses it. Thus, what we may immediately notice is that the current Brazilian designers, in a stereotypical way and far from reality, associate this style to a standard of simplicity, tranquility, craftsmanship, earthy colors, and to certain innocence when compared urban citizen. Representing also a site to search national roots.

Keywords Fashion; Identity; Country; "Luar do Sertão" 


\section{A moda do sertão: uma construção de identidade nacional a partir da canção "Luar do Sertão"}

0 sertão e o mundo caipira ganharam características (imagéticas, sensoriais, emocionais etc.) fortemente delineadas pela narrativa musical, em discursos que ecoam em todos os setores da sociedade, influenciando o comportamento, os gostos e as relações sociais. Nesse universo, emerge a canção "Luar do Sertão", lançada em 1914, como um ícone da música sertaneja, e com papel destacado na caracterização do gênero e na composição de identidades nacionais.

o fonograma utilizado para análise e de autoria de Catulo da Paixão Cearense e conta com a interpretação de Eduardo Neves e coro. A escolha desta canção se deve principalmente ao fato de que desde sua criação esta música vem sendo um estandarte notável da população do interior do Brasil de forma geral por vários períodos da história brasileira, que acaba sendo unificada sob os estereótipos de caipira e sertanejo, independentemente da localização geográfica. Generalização esta, que vem sofrendo novas interpretações conforme os interesses hegemônicos e acontecimentos sociais de cada época. Servindo ainda hoje, como ícone ilustrativo e unificador do sertanejo nacional, do caipira e dos habitantes de áreas rurais.

Uma vez que ela se destaca no cenário nacional há quase um século, nota-se que sua mensagem vem sendo reiterada e remodelada ao longo dos tempos, conforme os interesses hegemônicos e acontecimentos sociais de cada época, conferindo imagens generalizantes a estes segmentos da população brasileira e que interferem diretamente na concepção de povo do imaginário coletivo nacional. Em vista disso, pode-se afirmar que a canção vem fazendo parte de uma narrativa de nação desde sua criação e que influencia ainda hoje a visão sobre as regiões interioranas do país.

Partindo disso, após analisar o fonograma de "Luar do Sertão", foram selecionadas algumas características principais e comparadas com a leitura do sistema de moda nacional acerca do tema "sertanejo", fundamentada pela seleção de imagens de coleções de moda brasileira que o abordavam. 0 objetivo disso, é discutir as possibilidades de expressão de uma noção de identidade constituída pela canção, através da apropriação desses conceitos apreendidos pela cultura contemporânea na esfera das imagens produzidas pela moda, e que compõe com seus fragmentos possibilidades de diálogo para uma compreensão da história passada e do tempo presente. Pois as noções contemporâneas do sertanejo, caipira e interiorano brasileiro são perpetuados pela enxurrada de imagens e pela massificação, próprias do sistema de moda, configuram um diálogo entre a concepção generalizada da população e o próprio entendimento que é transmitido por essas coleções de moda.

Deste modo, o que se percebe de forma mais imediata, é que os estilistas brasileiros atuais, de forma estereotipada e distante da realidade, associam a este estilo o padrão da simplicidade, da tranquilidade, do trabalho artesanal, das cores terrosas, e de uma certa inocência quando comparado ao cidadão urbano. Representando ainda, um local de busca pelas raízes nacionais, tal qual Mário de Andrade definiu nos anos de 1920 na tentativa de encontrar um tipos brasileiros. Entretanto, o que ocorre é a interação da canção "Luar do Sertão", da moda e de tantos 
outros setores da sociedade na invenção de algo que se denomina identidade, em uma negociação constante.

\section{Identidade nacional e Luar do Sertão}

Contudo, a distinção entre música caipira e música sertaneja, que seria marcada pelas diferentes regiões do país, acabou sendo diluída. Como afirma Rosa Napomuceno, "as fronteiras entre o caipira e o sertanejo se [diluíram] sob o prisma da cidade" (2005, p.106), de modo que música sertaneja, conforme Allan de Paula Oliveira, passou a ser vista como um grande conjunto de diferentes subgêneros, como moda-de-viola, catira, cana-verde, batidão, guarânia, pagode-de-viola, toada, corrido, polca mato-grossense, dentre outros, unificados pela estabilidade em termos de estrutura, temática e estilo (2009, p.35). Atualmente, José Ramos Tinhorão, José de Souza Martins e Waldenyr Caldas apresentam uma nova leitura, na qual a música caipira é diretamente ligada a seu contexto ritual de produção, religioso ou profano (como os cantos de trabalho e lazer) e ao folclore do interior paulista, enquanto a música sertaneja se apresenta como um produto eminentemente de consumo, que avança os centros urbanos das regiões Sul, Sudeste e Centro-0este. Nas palavras de Tinhorão:

A música sertaneja - assim chamada pelas fábricas de discos e pelos locutores de programas de rádio destinados ao interior - engloba sob esse nome uma variedade enorme de gêneros de músicas particulares de uma vasta zona geográfica em que predomina o som de um determinado instrumento: a viola de cinco cordas duplas, mais conhecida como viola caipira (2006).

Porém, para fins desta discussão, existe a compreensão de que os termos "caipira" e "sertanejo" passaram a ser utilizados como desígnio da população do interior do país de forma generalizada. Uma vez que, essas atribuições foram postas justamente pelo público urbano em ebulição em meados de 1920, para marcar as diferenças entre os dois ambientes. A generalização dos termos fortalece o caráter de unidade nacional no começo do século XX, ao passo que homogeniza uma boa parte do país que não está inclusa no eixo de desenvolvimento industrial, através do apelo sentimental de saudades da terra original. 0 caipira do sul, por exemplo, é o colono, e assim funciona pelo Brasil afora. Logo, dentro deste viés, aqui, a música caipira e sertaneja será tratada como um mesmo gênero, bem como quando indicar seus sujeitos.

Desta maneira, a música torna-se também metáfora da nação, opera como representação simbólica das relações entre passado, presente e futuro e, atua como elo de consolidação de discursos nacionais. Pois como atesta Chris Southeott, uma nação se constrói a partir da interpretação dos elementos da cultura (língua, território, folclore, música, etc.), os quais organizam a sociedade ao passo que se 
transformam em mitos (apud RIVERA, 2000, p.200). Seguindo essa proposição, os projetos populistas de 1930 no Brasil, oportunamente se apoiaram em manifestações artísticas que pudessem traduzir simbolicamente o conceito então almejado de povo, algo do tipo divertido, porém ordeiro, patriota e trabalhador (CARVALHO, 1998, p. 261). Destacando-se a música, como instrumento associado aos sistemas de dominação hegemônicos que promove um diálogo entre o Estado e as grandes camadas populares, um elemento de informação que muitas vezes passa despercebido. Destarte, conforme Attali,

Toda a música, qualquer organização de sons é, assim, uma ferramenta para a criação ou consolidação de uma comunidade, de uma totalidade. É o que conecta o centro do poder aos seus sujeitos e, desta maneira, geralmente é um atributo do poder em todas as suas formas. Portanto, qualquer teoria do poder hoje deve incluir uma teoria da localização do ruído e da sua relação com a forma (1985:6, apud RIVERA, 2000, p. 148).

Se a "Aquarela do Brasil" (e o samba de forma geral, acompanhado dos retoques do Estado Novo) pintava o cartão-postal do Brasil tropical no exterior, "Luar do Sertão" ilustrava para os próprios brasileiros, o que seria o interior do país e seu estilo de vida. Em uma moldura onde apenas cabiam os opostos campo e cidade, criava-se um quadro idealizado da massa não absorvida pela recente industrialização do país. Evidenciando pela música, uma narrativa que denota estereótipos. Os quais, segundo Homi K. Bhabha (1983, p.18), são das mais eficientes estratégias de discurso, pois demarcam posições sociais através de identificações, eles subsidiam e asseguram os discursos de mudanças de conjunturas históricas e informam as estratégias de individuação e marginalização. Consequentemente, pode-se notar que a construção imagética e subjetiva do homem rural, se fundamentou nas histórias rurais e na música sertaneja, pautadas, sobretudo, pelo olhar urbano. Destarte, mediante a ideologia vigente nas primeiras décadas do século XX, o citadino assume uma posição de superioridade ao caipira. Mário de Andrade em sua literatura, Marcelo Tupinambá (codinome de Fernando Álvares Lobo) em suas canções e Catulo da Paixão Cearense em suas poesias, ajudaram a cristalizar essa imagem e a fomentar esse distanciamento, tão bem colocados em "Luar do Sertão", que exalta romanticamente o ambiente rural como uma terra "sem tempo e sem fronteiras" (TINHORÃO, 1991, p.186), o oposto da cidade, onde até o prazer é limitado pelo tempo e pelo trabalho.

Se a lua nasce por detrás, da verde mata,

Mais parece um sol de prata,

Prateando a solidão,

E a gente pega na viola que ponteia,

E a canção é a lua cheia,

A nos nascer no coração (CEARENSE, 1914) 
"Luar do Sertão" conta uma história do interior do Brasil, que auxilia o Estado Novo na exaltação à ordem, à disciplina e ao trabalho honesto, pois o trabalhador rural bem elucida esse quadro em "Luar do Sertão" e em outras canções de temática rural. Com os anos 1930, a música que se dissipava pelo país carregava uma linguagem simbólica do nacional. 0 povo que era homenageado e imaginado nas músicas emblemáticas do projeto populista de 1930 e 1940 mostrava um povo ingênuo, rude e simples, longe do anti-modelo anárquico e das massas urbanas que povoavam as cidades. Desta maneira, a música sertaneja, apesar de não ser representativa do país como um todo, dentro do projeto getulista de nação tinha a capacidade de unificar a população caipira, de retirantes e de imigrantes. Integrando, portanto, traços de várias regiões (interior, sertão, centro-oeste etc.) sob uma ótica romântica, de saudosismo e de enaltecimento, que mesmo não sendo contemplativa da realidade, era aceita por pintar um belo quadro de um contingente negligenciado mediante o furor do progresso (KRAUSCHE, 1983, p.41). Assim, apesar de "Luar do Sertão" ter origem em 1914, o governo de Getúlio Vargas não a fez passar despercebida, pois logo incorporou o sertão na transmissão de sua ideologia nacionalista, tanto que foi na década de 30 sua maior repercussão. A partir de 1939, a canção tornou-se prefixo da Rádio Nacional do Rio de Janeiro por iniciativa do Almirante (SEVERIANO; MELLO, 2006, p.39). Nessa ocasião, torna-se claro como o governo percebe que a rádio pode instrumentalizar um processo de "integração nacional e o estabelecimento de uma 'linguagem' de dominação" (CONTIER, 1991:10, apud RIVERA, 2000, p. 148). Entrementes, percebe-se que as políticas culturais do regime ditatorial militar foram alimentadas pela construção de uma tradição, como categoriza Napolitano, a qual seria responsável por unificar todo um território sob a égide de seu domínio (2008, p.246).

Assim, é possível fazer uma ligação entre as possibilidades de expressão de uma noção de identidade através da música "Luar do Sertão", de como ela se relaciona à história e, por conseguinte, como é apropriada pelo sistema de moda, através dos significados estabelecidos pelos produtos de moda. 0 sistema de moda, por conseguinte, se constitui na história, no contexto em que estão arraigados esses produtos e nas construções ao seu redor, ou seja, quem os utiliza, local de sua inserção, a publicidade que os promove e a mídia que alimenta as expectativas, além do próprio consumo. Deste modo, as marcas utilizam um conceito de sertanejo, que de fato faz alusão aos estereótipos marcados por narrativas musicais como "Luar do Sertão", em novas versões relacionadas aos anseios e aspirações de cada momento. 0 tema caipira pode ser para a moda, aglutinador de um público que se sente atraído pela ideia de uma identidade nacional com tons de folclore, que compra a ideia de sentir-se próximo às quiméricas raízes brasileiras para assumir uma posição de segurança frente à uma sociedade instável, de relações primordialmente comerciais e efêmera. 0 poder do quadro pintado pela canção, bem como pela mensagem disseminada por outros veículos de comunicação, é tão forte, que fomenta a saudade de algo que nunca se teve. 0 sertão/paraíso 
idílico é claustro tão aconchegante, que desperta o desejo de milhares de cidadão assolados pelo ritmo frenético do capitalismo de possuírem um pedacinho desse lugar, nem que seja numa peça de roupa. Assim sendo, em tempos de modernidade líquida, o conforto do ambiente ilustrado por "Luar do Sertão" pode ser uma excelente proposta a ser transfigurada em moda.

\section{Vestindo sons e imagens}

0 sertão e o mundo caipira ganharam características (imagéticas, sensoriais, emocionais etc.) fortemente tracejadas e muito bem sedimentadas pela narrativa musical, em discursos que ecoam em todos os setores da sociedade, influenciando o comportamento, os gostos e as relações sociais. Não é a toa que também na moda, a imagem do sertão com frequência inspira calmaria, espiritualidade e nostalgia. Especialmente nos dias de hoje, esse discurso é reforçado por representar uma oposição ao sistema de relações vigente, globalizadas e sem tempo para espiritualidade ou autoconhecimento, que impõe um ritmo acelerado, que privilegia o consumo. Mediante essa crise de valores, o "fictício" mundo caipira readquire importância, ganha novos significados e abocanha novos adeptos urbanos. Torna-se popular na esfera de um zeitgeist' (espírito do tempo) que coordena um movimento de busca pelas raízes individuais, equilíbrio pessoal, paz, autenticidade e originalidade.

Esse ideal ocorre justamente pelo fato de as narrativas históricas em geral, especificamente a música, como vem sendo debatido nesse artigo, disseminarem uma identidade e uma imagem fantasiosa nesse tipo de discurso em relação ao interior, os quais "estruturam as formações discursivas e os processos de construção das subjetividades" (HOLLANDA, 1991), gerando um senso de consciência coletiva homogênea sobre algo que é desconhecido e heterogêneo.

Consequentemente, mesmo que seja claro que o sertanejo sofra influências dos acontecimentos mundiais e tenha sua cultura em mutação constante, como qualquer

1 Termo alemão cuja tradução é "espírito do tempo". Hegel o define como um espírito absoluto inscrito em todas as coisas, "símbolo do devir, do progresso e da perfeição", que absorve as ações dos atores (KERN, 2010, p.13). Dario Caldas divide o "espírito do tempo" em duas interpretações, a primeira o entende como um sinônimo de contemporaneidade, algo que está no ar, mas ainda não foi apreendido totalmente, pois está em formação. A segunda, num viés sociológico, como uma tônica também do contemporâneo que sintetiza os gostos, o clima intelectual, moral e cultural caracterizando um determinado período (2004, p.71). Para o campo da moda, as duas são pertinentes, pois ambas atuam na concepção de uma nova estética e dão as diretrizes para as novas tendências. Esses movimentos são percebidos conforme surgem sinais que se somam para projetar um mesmo significado, uma mesma mensagem, mesmo que por canais e códigos diferentes. Isto mostra que o zeitgeist define um momento estético que seria percebido por formas, volumes, cores, padronagens, materiais que, juntos, informam um mesmo propósito estilístico (BACK, 2008, p. 42). 
outro grupo social, ainda é visto com extrema distância, algo fora dos padrões urbanos e incomum na efêmera indústria da moda. Dessa maneira, esta última vem gradativamente enxergando com novos olhos o folclore, o sertão, a simplicidade e a caipirice, percebendo nessa vertente novas possibilidades a serem exploradas, um apelo às raízes da brasilidade e uma quebra de padrão, relembrando Mário de Andrade ${ }^{2}$ no começo do século XX.

Facilmente, a imagem do sertão se torna um retrato do Brasil principalmente para os brasileiros, adotado aqui como instrumento que desenha uma identidade brasileira na moda, trazendo seus elementos à tona como singularidades e símbolos fictícios de uma brasilidade pura e rústica, já que, como bem disse Simmel, mesmo que a moda se constitua apenas em sociedades urbanas e industrializadas, é no confronto à massificação que ela se perpetua (apud BAUMAN, 2005).

Para tanto, a simplicidade ganha novas feições conforme cada interpretação, sendo marcantes as cores terrosas e os trabalhos manuais, estes atuam como grandes diferencias na moda contemporânea, assinalada pela velocidade do prêt-à-porter em larga escala e pelo enxame de produtos barateados, são poucas as peças que ganham detalhes cuidadosos. Quando estes são frutos de artesanato ou feitos à mão, são ainda mais valorizados. Curioso, contudo, que os trabalhos manuais regionais recebam essa valorização de forma mais expressiva apenas quando são associados a artigos de vanguarda, ou a nomes e marcas já sedimentadas na tradição citadina e, não recebam o mesmo valor quando vistos em suas origens, nas mãos dos artesãos e artesãs da área rural, pois mediante um artesão é recorrente a prática da pechincha, e já perante uma vendedora de marca renomada não é comum se ver pechinchar o preço de uma blusa com renda feita à mão, sendo até mais fácil aceitar pagar mais caro por ela por conta deste último detalhe. Mesmo mediante a globalização, perante os grandes públicos consumidores continuam sendo supervalorizados os artigos dos shoppings. É precisamente por isso que para a moda se torna tão importante buscar novas fontes de inspiração que não sejam revistas e desfiles, este ramo agora se depara com novos desafios de criação em que se faz necessário desacelerar e correr atrás de conteúdo para suas obras, o qual pode residir perfeitamente no trabalho de artistas. Nesse caso, a moda atua como elo entre o global e o local, uma vez que faz com que traços da cultura local perdurem no tempo e sejam progressivamente relidos através do substrato artístico em que se apoia.

Dentro da moda brasileira, vários estilistas recorreram a artigos, elementos e formas tradicionais das áreas rurais, não obstante seus discursos tenham variado conforme cada momento histórico, podem ser revisitados e reinterpretados com

2 Mário de Andrade em seus trabalhos iniciais no começo dos anos 20 idealizava encontrar uma música genuinamente brasileira, estudou melodias folclóricas brasileiras ouvidas em diversas regiões do país, especialmente Nordeste e Minas Gerais, pois acreditava serem estes territórios distantes e não poluídos pelas influências estrangeiras massificadas da urbe (CASTAGNA, p.05). 
o passar dos anos. Nas décadas de 60 e 70, a estilista Zuzu Angel ao buscar sua leitura de brasilidade bebeu de elementos da cultura sertaneja nordestina, para tanto usou a tradicional renda de bilro cearense em seus vestidos, bordados de pedras brasileiras feitos à mão, rendas do norte e rendões nordestinos tingidos à mão com seda, a simples e colorida chita, se inspirou em Lampião e Maria Bonita e criou modelagens de vestidos, saias e blusas amplas e volumosas, lembrando as formas das rendeiras 3 .

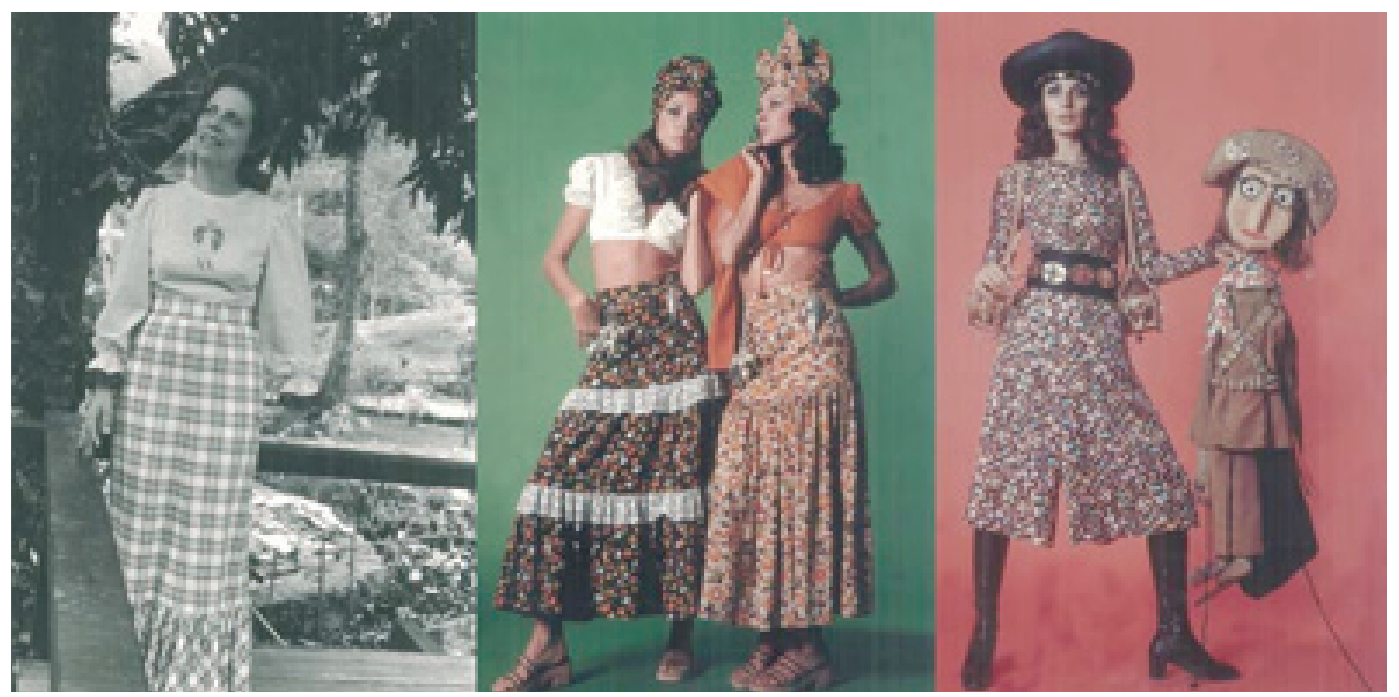

Figure 1 - Zuzu Angel. Revista Catarina, ed.7. 2006. Fonte: 〈http://www.revistacatarina.com.br/ portal/edicao.php?idEdicao $=18>$

Já a Cavalera, na coleção primavera-verão 2005/06 resgatou as saudades das foIhas secas, do sol e do "luar da minha terra", não deixando dúvidas de que queria apresentar um novo gênero, o cangaceiro urbano. Espetacularizando o tema, trouxe motocicletas no lugar dos cavalos e, com o auxílio performático do teatro oficina, criou a figura de um herói num contexto urbano/caboclo bastante confuso. Desfigurou a imagem de calmaria e tentou uma simbiose entre os modelos "loucos tempos modernos" e "Os Sertões" de Euclides da Cunha. Isso por meio de patchworks, chapéus de cangaceiro e Estampas de Padre Cícero e Nossa Senhora Aparecida em peças de design contemporâneo. Mas o apelo ao que é visto como "inerente" (atribuição equivocada e generalizada de identidade) ao sertanejo (leia-se o nordestino no caso da Cavalera) não parou por aqui, além das cores de terra e das peças puídas, a Cavalera conseguiu que o artesão filho do sapateiro de Lampião, confeccionasse a linha de bolsas e sapatos de couro que seriam comercializados em sua coleção feminina daquele verão, e de quebra, o artesão afirma

3 Instituto Zuzu Angel. Sobre Zuzu Angel, ver MARQUES, Dayse. Zuzu Angel: a identidade cultural brasileira através da moda. Dissertação de mestrado em história da arte. UFRJ- EBA. Rio de Janeiro: [s.n.], 1998. 
A moda do sertão: uma construção de identidade nacional a partir da canção "Luar do Sertão"

que o modelo dos sapatos é o mesmo que o que seu pai fazia para Maria Bonita. No fim das contas, o desfile sugeriu um personagem brasileiro-cangaceiro-rockeiro-cowboy (no estilo estado-unidense), mas apesar do apelo estereotipado, pelo menos parece que a Cavalera tentou comunicar que ser "caipira" pode ser cool (FERREIRA, 2005; PACCE, 2005).

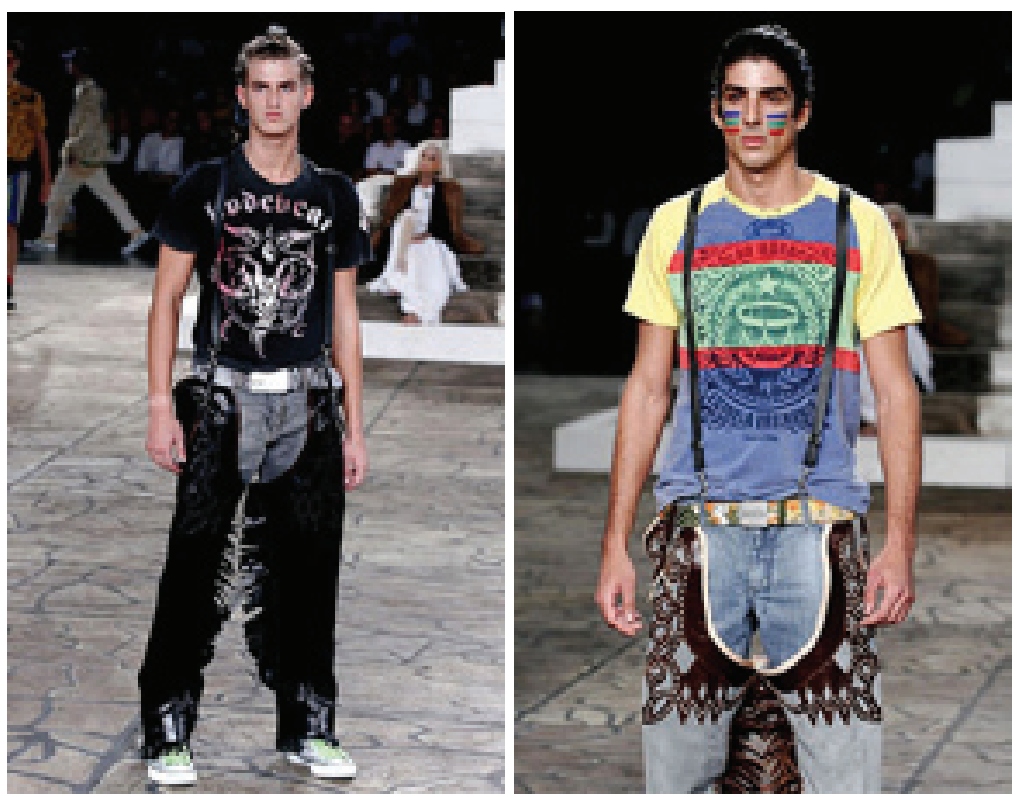

Figure 2 - Desfile Cavelera Sertão, primavera-verão 2005/2006. Fotos: Ricardo Tatto. Fonte: 〈http://www.flickr.com/photos/tatooestampas/3430013805/in/set-72157616609717898/>

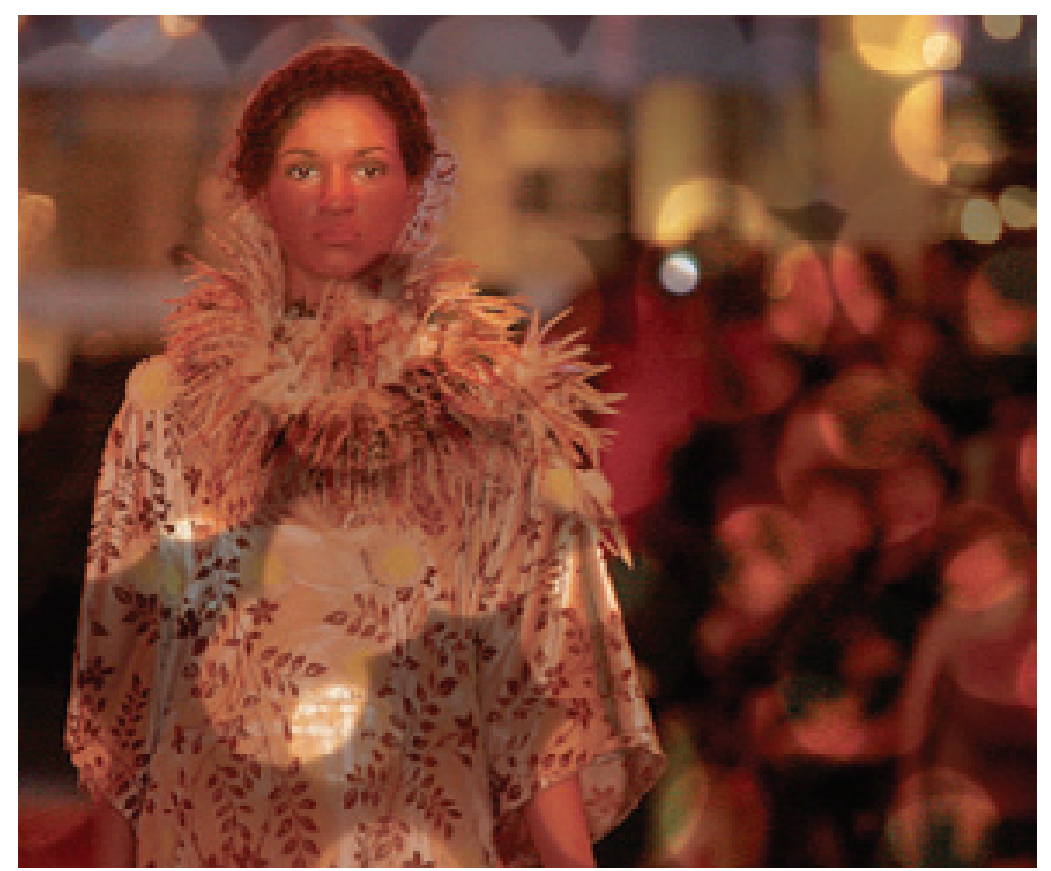

Figure 3 - Homenagem feita à Guimarães Rosa pelo estilista Ronaldo Fraga chega a Cordisburgo. In Minas Online. 25/07/2006. Fonte: < http://culturahomologa.mg.gov.br/?task=internađtsec=

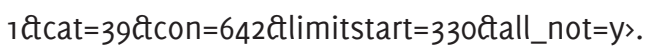


Outros vários exemplos ainda podem ser citados. Um designer brasileiro que se volta bastante à temática do sertão, aproveitando bastante os trabalhos manuais desenvolvidos nessa região, e os tratando como representação de uma identidade brasileira, é Lino Villaventura. Em sua coleção de inverno 1997 ele apresentou como conceito "a esperança do inverno que quase nunca chega [no sertão] e, quando vem, cai em forma de chuva" 79 e a de inverno 1999, com formas inspiradas nos lagartos que vivem nas dunas de Natal (QUEIROZ; BOTELHO, apud MARTINS, 2010, p.35).

Igualmente famoso por explorar temas da cultura brasileira, em 2006, a Coleção Primavera/Verão de Ronaldo Fraga teve como inspiração a obra de Guimarães Rosa, "Grande Sertão: Veredas", trazendo em sua coleção o universo seco, cheio de armadilhas do sertão em um diálogo entre cores, perfumes e texturas, a passarela do desfile era repleta de folhas secas e serragem colorida que formavam o desenho de cobra enrolada num chão de bichos, flores, caveiras e estrelas. As cores, inicialmente terrosas, a cenografia e a música criavam uma ambientação que transportava os presentes a uma outra dimensão, o sertão imaginado por Fraga. Nesse universo criado por ele destacavam-se as estrelas e a lua nas roupas. 0 sertão apareceria em outras oportunidades em seu repertório, falando da religiosidade que o caracteriza, do artesanato local e do Rio São Francisco que o alimenta.

Muitas outras coleções poderiam ser lembradas, todavia, o notável, é que todas as coleções trouxeram leituras particulares do sertão, materializadas pelas produtos de moda e pela atmosfera criada nos desfiles. Toda essa produção que evolve roupa, música, cenário e os valores culturais vigentes, criam narrativas que se estabelecem a partir do universo da moda no imaginário coletivo como representação desse meio e dessa cultura. Com isso, o que se nota é que a identidade é um objetivo, um esforço, algo a ser inventado e não descoberto, uma condição provisória negociável e revogável, que leva a compreensão de que as identidades flutuam no ar, sendo algumas de nossa própria escolha, e outras infladas e lançadas pelas pessoas a nossa volta, é uma negociação constante que busca livrar os fenômenos de seus significados estabelecidos e lhes dar novos, mudar a forma como ele está embutido no contexto da vida. Assim, a identidade nacional é forçada, chega como ficção que solidifica um fato num dado, como uma tentativa de conciliar demandas contraditórias e incompatíveis que delimitam uma imagem homogênea de nação através da sedução, limite de fronteiras, coerção e convencimento (BAUMAN, 2005, p.19-28).

Sendo a moda e a música dois grandes veículos de comunicação, bem como refletores das mudanças sociais que caminham em constante interação, cabe aos estudiosos desses ramos investigarem em que projeto de nação esses produtos de moda se inserem e qual o discurso e a função que seu consumo representa, a fim de contribuir com o refazer de várias histórias silenciadas e com a proliferação de intervenções setoriais. Conforme Heloísa Buarque de Hollanda, caminhar para uma quebra com modelos antigos de imperialismo cultural e econômico, e fazer desta realidade não mais pós-moderna, mas líquida (BAUMAN, 2005), uma "tática cuja eficácia é diretamente proporcional à sua luta contra a linguagem e ao seu compromisso com a desarticulação dos vários e sutis sistemas de dominação ainda hegemônicos" (HOLLANDA, 1991). 


\section{Referências Bibliográficas}

> BACK, Suzana. Pesquisa de tendências - um modelo de referência para pesquisa prospectiva. 2008. 138f. Dissertação (Mestrado em Engenharia de Produção) - Programa de Pós-Graduação em Engenharia de Produção, UFSC, Florianópolis.

$>$ BAUMAN, Zygmunt. Identidade: entrevista a Benedetto Vecchi. Rio de Janeiro : J. Zahar, 2005.

> BHABHA, Homi K. Disseminação - 0 Tempo, a Narrativa e as Margens da Nação Moderna. In 0 local da cultura. Tradução de Myriam Ávila, Eliana Lourenço de Lima Reis, Cláucia Renate Gonçalves. Belo Horizonte: Ed. UFMG, 1998, p. 198-238.

$>$ BHABHA, Homi K. The other question... Homi K. Bhabha reconsiders the stereotype and colonial discourse. In Screen 24, 1983, p. 18-36. Disponivel em: <http:// screen.oxfordjournals.org/cgi/reprint/24/6/18.pdf>. Acesso em: 10 de dezembro de 2010.

> CALDAS, Dario. Observatório de sinais: Teoria e prática de pesquisa de tendências. Rio de Janeiro: Ed. Senac, 2004.

> CARVALHO, José Murilo. Brasil: nações imaginadas. In Pontos e bordados: escritos de história e política. Belo Horizonte: UFMG, 1998.p.233-289.

> FARINACl, Antonio. Filho do sapateiro de Lampião fará bolsas para Cavalera. Em UOL Estilo, 04 de julho de 2005. Disponível em: < http://estilo.uol.com.br/moda/ spfw/ultnot/2005/07/04/ult2993u301.jhtm>. Acesso em: 21 de janeiro de 2010.

> FERREIRA, Nathália. Meninos da Cavalera surgem como cangaceiros modernos. Em UOL Estilo, 01 de julho de 2005. Disponível em: < http://estilo.uol.com.br/ moda/ultnot/2005/07/01/ult26u19293.jhtm>. Acesso em: 21 de janeiro de 2010.

> HOLLANDA, Heloísa Buarque. Políticas da teoria, introdução. In Pós-Modernismo e Política. Rio de Janeiro: Editora Rocco, 1991, 2š edição, p. 7-14, 1992. Disponível em: 〈http://www.heloisabuarquedehollanda.com.br/? $\mathrm{p}=411 \mathrm{ctcat}=6$ 〉. Acesso em 10 de dezembro de 2009.

> Instituto Zuzu Angel. Zuzu Angel inspira identidade e poesia na moda brasileira. 2008. Disponível em: 〈http://www.zuzuangel.com.br/html/zuzu.asp〉. Acesso em: 19 de jan. de 2010.

> KERN, Maria Lúcia Bastos. Imagem, historiografia, memória e tempo. In Revista ArtCultura. Uberlândia (MG), Universidade Federal de Uberlândia- UFU, v.12, n. 21, jul./ dez. 2010. ISSN Versão on-line: 2178-3845. Disponível em: < http://www. artcultura.inhis.ufu.br/PDF21/m_kern.pdf >. Acesso em: 18 de maio de 2011.

> KRAUSCHE, Valter. Música popular brasileira. Brasiliense: São Paulo, 1983.

> MARTINS, Camila. Made in Brazil: narrativas de identidade na moda. 201063 p.

: TCC (graduação) - Universidade do Estado de Santa Catarina, Centro de Artes, curso de Moda, Florianópolis, 2010.

> NAPOLITANO, Marcos. A patrimonialização da música brasileira: entre a tradição e a ruptura. Em ArtCultura, Uberlândia, v. 10, n. 17, p. 245-249, jul.-dez. 2008. 
> PACCE, Lílian. SPFW primavera-verão 2005/06 - Quarto dia. Em MSN Moda. 01 de julho de 2005. Disponível em: < http://msn.lilianpacce.com.br/fashionteca/spfwprimavera-verao-200506-quarto-dia/>. Acesso em: 21 de janeiro de 2010.

> RIVERA, Mareia Quintero. A cor e o som da nação, a ideia de mestiçagem na crítica musical do caribe hispânico e do Brasil (1928-1948). Annablume Editora: São Paulo, 2000.

> SEVERIANO, Jairo; MELLO, Zuza Homem de. A canção no tempo: 85 anos de músicas brasileiras. 5.ed. Ed. 34: São Paulo, 2006.

> TINHORÃo, José Ramos. Música sertaneja é esse negócio. In: Cultura Popular: Temas e Questões, Editora 34, 2š Edição, 2006. Disponível em: < http://www.anovademocracia.com.br/index.php?option=com_contentてttask=viewđtid=2348ctltemid =105>. Acesso em: 31 de março de 2010 .

$>$ Pequena história da música popular: da modinha à lambada. 6ed. Art Editora: São Paulo, 1991.

\section{Discografia}

> CEARENSE, Catulo da Paixão. Luar do sertão. Intérprete: Eduardo das Neves. Álbum 120911: Odeon, p1914. Lado A, 78 rpm. Coleção Humberto Franceschi. Disponivel em: 〈http://homolog.ims.com.br/cgi-bin/wxis.exe/iah/〉. Acesso em: 16 de fevereiro de 2010.

*Produzido durante o Projeto de Iniciação Científica Brasil por suas Aparências - A República das Imagens, com bolsa PROBIC- UDESC, período 2009-2010.

Káritha Bernardo de Macedo, bacharel em Moda - Universidade do Estado de Santa Catarina- UDESC

karitha23@yahoo.com.br

Mara Rúbia Sant'Anna-Muller, doutora em História (2005) pela Universidade Federal do Rio Grande do Sul/EHESS (FR); professora efetiva da Universidade do Estado de Santa Catarina; Strasbourg- França

sant.anna.udesc@gmail.com 